\title{
Teacher Self-Efficacy and Collective Teacher Efficacy: Relations with Perceived Job Resources and Job Demands, Feeling of Belonging, and Teacher Engagement
}

\author{
Einar M. Skaalvik ${ }^{1 *}$, Sidsel Skaalvik ${ }^{2}$ \\ ${ }^{1}$ NTNU Social Research, Trondheim, Norway \\ ${ }^{2}$ Norwegian University of Science and Technology (NTNU), Trondheim, Norway \\ Email: *einar.skaalvik@ntnu.no, sidsel.skaalvik@ntnu.no
}

How to cite this paper: Skaalvik, E. M., \& Skaalvik S. (2019). Teacher Self-Efficacy and Collective Teacher Efficacy: Relations with Perceived Job Resources and Job Demands, Feeling of Belonging, and Teacher Engagement. Creative Education, 10, 1400-1424.

https://doi.org/10.4236/ce.2019.107104

Received: May 1, 2019

Accepted: July 7, 2019

Published: July 10, 2019

Copyright $\odot 2019$ by author(s) and Scientific Research Publishing Inc. This work is licensed under the Creative Commons Attribution International License (CC BY 4.0).

http://creativecommons.org/licenses/by/4.0/

(c) $\underset{\mathrm{EY}}{\mathrm{B}}$ Open Access

\begin{abstract}
The purpose of this study was to explore how collective teacher efficacy and teacher self-efficacy were related to teachers' perceptions of job resources and job demands in the working environment at school, teachers' feeling of belonging and teacher engagement. Three job resources were included: positive and supportive relations with colleagues, positive and supportive relations with the school leadership, and shared goals and values. Three job demands were also included: discipline problems, time pressure, and student diversity. Participants in the study were seven hundred and sixty teachers in elementary school (grade 1 - 7) and middle school (grade 8 - 10). Data were analyzed by means of confirmatory factor analysis and SEM analyses. The SEM analysis revealed that all job resources were positively associated with collective efficacy and belonging whereas teacher self-efficacy was positively associated with teacher engagement. The SEM analyses also indicated that the job resources were indirectly associated with teacher self-efficacy, mediated through collective efficacy and that collective efficacy was indirectly associated with engagement, mediated through teacher self-efficacy.
\end{abstract}

\section{Keywords}

Teacher Self-Efficacy, Collective Teacher Efficacy, Teacher Engagement, Belonging, Job Resources

\section{Introduction}

Teacher self-efficacy, teachers' beliefs in their abilities to organize and execute 
the courses of action required to produce given attainments has received much attention in educational research the past couple of decades. Research evidence reveals that teacher self-efficacy is related to several positive outcomes, for instance, higher levels of teacher engagement and job-satisfaction and lower levels of stress and burnout (Aldridge \& Fraser, 2016; Aloe, Amo, \& Shanahan, 2014; Shoji et al., 2016; Stephanou \& Oikonomou, 2018). Less attention has been given to collective teacher efficacy, which refers to teachers' "beliefs about the ability both of the team and of the faculty of teachers at the school to execute courses of action required to produce given attainments" (Skaalvik \& Skaalvik, 2007: p. 613). Nevertheless, the available research indicates that collective teacher efficacy is also positively related to teacher motivation and job satisfaction and negatively related to teacher burnout (Klassen, Usher, \& Bong, 2010; Stephanou \& Oikonomou, 2018). However, studies of the relative impact of these constructs on teachers' feeling of belonging and engagement are scarce (Stephanou \& Oikonomou, 2018). The purpose of the present study was to explore the relation between collective teacher efficacy and teacher self-efficacy and how these constructs were related to teachers' perceptions of the working environment at school, teachers feeling of belonging and teacher engagement.

\section{Theoretical Framework}

\subsection{Teacher Self-Efficacy}

As noted by Mojavezi and Tamiz (2012) most research on teacher self-efficacy has been based on Bandura's conceptualization of self-efficacy, which is grounded in social cognitive theory (Bandura, 1977; Bandura, 1997; Bandura, 2006). Within this framework, self-efficacy is conceptualized as a multidimensional and domain-specific construct. This conceptualization has been supported in a number of studies (Avanzi et al., 2013; Klassen et al., 2009; Skaalvik \& Skaalvik, 2007).

According to Bandura (1997), self-efficacy beliefs are influenced by four principal sources of information: enactive mastery experiences, vicarious experiences, verbal persuasion, and physiological and affective states. Bandura points out that "enactive mastery experiences are the most influential source of self-efficacy because they provide the most authentic evidence of whether one can master whatever it takes to succeed" (p. 80). As pointed out by Pajares (1997), "individuals gauge the effects of their actions, and their interpretations of these effects help create their efficacy beliefs" (p. 2). Following this reasoning, we expect that a principal source of teacher self-efficacy is prior perceptions of successful or less successful teaching experiences, including experiences of classroom management, instructing and motivating students, and cooperating with colleagues and parents. We also assume that such experiences may be affected by job demands and job resources in the working environment at school. We did not include a measure of physiological responses in this study because we were concerned with associations between teachers' perceptions of aspects of the 
school environment and self-efficacy, collective efficacy, belonging and engagement.

According to the Job Demands-Resources (JD-R) model, there are two categories of work characteristics in all occupations: job demands and job resources (Demerouti, Bakker, Nachreiner, \& Schaufeli, 2001; Bakker \& Demerouti, 2006; Hakanen, Bakker, Nachreiner, \& Schaufeli, 2006). Demerouti et al. (2001) define job demands as "those physical, social, or organizational aspects of the job that require sustained physical or mental effort" (p. 501). Because job demands require sustained effort they are supposed to be associated with physical or psychological costs and may, therefore, result in emotional exhaustion (Demerouti et al. 2001). According to Demerouti et al. (2001), job resources refer to physical, psychological, social, and organizational aspects of the job that: 1) help achieve work goals, 2) reduce job demands or the consequences of job demands, and 3) stimulate personal growth and development.

The JD-R model distinguishes between two relatively independent processes: 1) a health impairment process in which job demands may lead to exhaustion and negative affect and 2) a motivational process in which job resources may increase job satisfaction and engagement (Bakker \& Demerouti, 2014). The JD-R model also proposes an interaction between job demands and job resources (Bakker \& Demerouti, 2006). For instance, discipline problems (a job demand) may affect teacher self-efficacy negatively. In this study, we were concerned with motivational processes which according to the model may be positively affected by job resources and negatively affected by job demands.

Researchers have identified a number of potential job demands in the teacher profession, for instance, time pressure, discipline problems, low student motivation, large student diversity, conflicts with colleagues, lack of administrative support, and value conflicts (Betoret \& Artiga, 2010; Collie, Shapka, \& Perry, 2012; Fernet, Guay, Senécal, \& Austin, 2012; Friedman, 1995; Hakanen, Bakker, \& Schaufeli, 2006; Klassen \& Chiu, 2010; Kokkinos, 2007; Shernoff, Mehta, Atkins, Torf, \& Spencer, 2011; Skaalvik \& Skaalvik, 2011a; Skaalvik \& Skaalvik, 2015). In particular, empirical research on teacher self-efficacy has shown that discipline problems and low student motivation are associated with lower teacher self-efficacy (Collie et al., 2012; Fernet et al., 2012; Gilbert, Adesope, \& Schroeder, 2014; Klassen \& Chiu, 2010; Klassen \& Chiu, 2011; Klassen et al., 2013; Skaalvik \& Skaalvik, 2016). These findings indicate that those job demands that interfere with the instructional and learning processes and with teachers' goal attainment are most strongly associated with teacher self-efficacy.

On the other hand, teaching experiences may be positively affected by job resources. Previous research reveals that positive and supportive social relations are associated with engagement, the feeling of belonging, and job satisfaction, but also with lower levels of burnout (Hakanen et al., 2006; Pines \& Aronson, 1988; Simbula, Guglielmi, \& Schaufeli, 2011; Skaalvik \& Skaalvik, 2011a; Skaalvik \& Skaalvik, 2017a). Moreover, social support, both from the school administration and from colleagues have been shown to be positively associated with teacher 
self-efficacy (Aldridge \& Fraser, 2016; Capa Aydin \& Woolfolk Hoy, 2005; Tschannen-Moran \& Woolfolk Hoy, 2007). Skaalvik and Skaalvik (2016) also found that the lack of supervisory support was negatively related to teacher self-efficacy.

A potential job resource that is less frequently studied is value consonance. Skaalvik and Skaalvik (2011a) defined value consonance as "the degree to which teachers feel that they share the prevailing norms and values at the school where they are teaching, for instance what goals should be pursued, what content should be emphasized, and what educational means and methods should be used" (p. 1031). They proposed that value consonance may be an important job resource in the teaching profession because many teachers are driven by values, ethical considerations, and intrinsic motivation (Sahlberg, 2010). According to Skaalvik and Skaalvik (2017c), "A teacher who feels that the prevailing norms, values and practices at the school are incompatible with her or his own values may experience what Rosenberg $(1977 ; 1979)$ referred to as contextual dissonance" (p. 779). As explained by Rosenberg (1977; 1979), a contextual dissonance may result in a feeling of not belonging, a feeling that one does not fit, that one is out of it, somehow wrong, which in turn may affect the teacher's belief in his or her competence negatively. Hence, we expected value consonance to be positively related to both teacher self-efficacy and teachers' feeling of belonging. These expectations are supported in previous research showing that value consonance is positively associated with teachers' feeling of belonging (Skaalvik \& Skaalvik, 2011a). Skaalvik and Skaalvik (2016) also found that lack of value consonance was predictive of lower teacher self-efficacy.

According to social cognitive theory, "efficacy beliefs determine how environmental opportunities and impediments are viewed" (Bandura, 2006: p. 4). Therefore, efficacy beliefs influence people's goals, motivation, and behaviors. Research evidence confirms that teacher self-efficacy is associated with teacher motivation and well-being, for instance higher levels of teacher engagement, job satisfaction, and commitment, and lower levels of burnout and motivation to leave the teaching profession (Aldridge \& Fraser, 2016; Avanzi et al., 2012; Brouwers \& Tomic, 2000; Caprara, Barbaranelli, Borgogni, \& Steca, 2003; Collie et al., 2012; Gilbert et al., 2014; Klassen \& Chiu, 2010; Klassen et al., 2013; Saricam \& Sakiz, 2014; Skaalvik \& Skaalvik, 2007; 2010; 2014; 2016; Stephanou \& Oikonomou, 2018; Zee \& Koomen, 2016). We, therefore, expected that teachers' self-efficacy beliefs would be positively associated with engagement.

In summary, we expected that teacher self-efficacy would, through teaching experiences, be positively associated with job resources and negatively associated with job demands. For instance, the self-efficacy of a science teacher may be influenced by his or her perception of demands and resources that may make the task more difficult or easier to conduct. Thus, teacher's self-efficacy will likely be positively affected by a supportive social environment and the experience of value consonance, and negatively affected by job demands, for instance, discipline problems. I turn, we expected that teacher self-efficacy would positively predict teacher engagement. 


\subsection{Collective Teacher Efficacy}

Bandura (1997) reminds us that many challenges, for instance in a school, requires that people work together. He, therefore, underscores the importance of developing beliefs that people can succeed through their collective efforts. According to Klassen (2010: p. 342), collective teacher efficacy beliefs reflect "teachers' perceptions of group-level attributes; that is, judgments of the capabilities of the staff or school to which they belong". Guidetti, Viotti, Bruno, \& Converso (2018) describe collective teacher efficacy as "the teachers' beliefs that the school as a whole can implement and organize courses of actions affecting students and their levels of attainments" (p. 199). Thus, collective efficacy beliefs center on the group's operative capabilities (Bandura, 1997).

Collective teacher efficacy must be distinguished from individual teacher self-efficacy. For instance, a particular teacher may have high efficacy beliefs related to his or her own teaching, yet have low expectations regarding the abilities of the teacher collegium at the school. Under such a condition the teacher may concentrate on his own teaching and strive to keep control in her or his own classes.

Although collective efficacy must be distinguished from individual self-efficacy several researchers assume that the four sources of individual self-efficacy (see above) also apply at the group level (Goddard, Hoy, \& Hoy, 2004). Researchers particularly emphasize mastery experiences as the most powerful source of collective efficacy (Adams \& Forsyth, 2006; Goddard et al., 2004). Goddard et al. (2004) also emphasize observation as a source of collective efficacy. We suggest that mastery experiences that result from collaboration and joint effort, for instance, a joint effort to reduce discipline problems at school, are particularly suited for increasing collective efficacy beliefs because such experiences demonstrate what "we, as teachers of this school" can accomplish together. Also, we expect that mastery experiences that result from advice and support from colleagues or supervisors may enhance collective teacher efficacy because these experiences also result from the shared effort. Moreover, such experiences should be expected to increase the teachers' beliefs that, when needed, they can get help and support from their colleagues or supervisors. Also, in a collaborative and supportive collegial environment we expect that observing successful colleagues may enhance collective efficacy. In such an environment the observation of successful colleagues may likely increase both the belief in the ability of the colleagues and the belief that the colleagues will provide advice and support when needed. Also, in schools that are characterized by a supportive social environment, we expect that teachers learn from each other and that this collective learning increases collective teacher efficacy. Succeeding after strategic planning in supportive teams should therefore be particularly suited for enhancing collective efficacy. Hence, the development of collective efficacy does not require that the teachers collaborate about the actual instruction of students. This is important, because, even in schools where teachers are organized in teams, the actual 
teaching is done by individual teachers.

In the teaching profession, we also expect value consonance, a common understanding of educational goals and values (see 2.1. Teacher self-efficacy), to be positively related to collective teacher efficacy. In schools where both teachers and the school administration have a common understanding of goals and values we expect teachers to be more likely to share their experiences, help and support each other, and to learn from each other. Hence, a reasonable assumption is that a common understanding of educational goals and values is an important prerequisite for the development of collective teacher efficacy.

Supporting these reflections, empirical studies indicate that supportive and positive interpersonal relations with colleagues, the school administration, and parents are positively related to collective teacher efficacy (Parks, Solmon, \& Lee, 2007; Viel-Ruma, Houchins, \& Jolivette, 2010). Avanzi et al. (2015) also found that collective teacher efficacy was associated with the perception of working in a supportive environment and Skaalvik and Skaalvik (2010), in a SEM analysis, found that supervisory support strongly predicted teachers' perception of collective efficacy (beta $=.50)$.

Research also indicates that collective teacher efficacy is associated with positive outcomes. Viel-Ruma et al. (2010) found that collective teacher efficacy was positively related to teachers' job satisfaction and Caprara, Barbaranelli, Borgogni, Petitta, \& Rubinacci (2003) found that collective teacher efficacy was strongly and positively related to both job satisfaction and emotional commitment. Stephanou \& Oikonomou (2018) showed that both teacher self-efficacy and collective teacher efficacy correlated around .50 with enthusiasm and job satisfaction and both Avanzi et al. (2015) and Skaalvik and Skaalvik (2007) reported that collective teacher efficacy was associated with lower levels of teacher burnout. Thus, although research on collective teacher efficacy is more limited than research on teacher self-efficacy, the available research shows that both these constructs are positively associated with measures of teacher motivation and well-being and negatively associated with stress and burnout.

\subsection{Relations between Teacher Self-Efficacy and Collective Efficacy}

The relation between teacher self-efficacy and collective teacher efficacy has been explored in several studies. These studies consequently show that the two constructs are positively correlated. Correlations between .35 and .55 are reported (Caprara, Barbaranelli, Borgogni, \& Steca, 2003; Caprara, Barbaranelli, Borgogni, Petitta, Rubinacci, 2003; Kurt, Duyar, \& Calik, 2012; Malinen \& Savolainen, 2016; Skaalvik \& Skaalvik, 2007; Viel-Ruma et al., 2010). Even higher correlations were reported in a study of Greek teachers in both primary and secondary school (Stephanou \& Oikonomou, 2018). Skaalvik and Skaalvik (2010) also found positive correlations between .29 and .45 between collective teacher efficacy and each of the six dimensions measured in the Norwegian Teacher Self-Efficacy scale. These studies only show associations between the constructs, whereas studies of 
causal relations are lacking.

Most studies of teacher self-efficacy and collective teacher efficacy have included only one of these constructs. However, because teacher self-efficacy and collective efficacy are positively correlated, studies including one of these constructs tell us little about the relative associations with the constructs. The importance of including both constructs is indicated in a few studies. Whereas Viel-Ruma et al. (2010) found that both individual self-efficacy and collective teacher efficacy were positively correlated with teacher job satisfaction, a regression analysis revealed that, when controlled for individual self-efficacy, collective efficacy was not significantly related to job satisfaction. In a study of Norwegian teachers Skaalvik and Skaalvik (2007) found correlations around .30 between collective teacher efficacy and indicators of teacher burnout. However, in a SEM analysis including self-efficacy they found no direct association between collective efficacy on teacher burnout. The association between collective efficacy and burnout was in the SEM analysis mediated through individual teacher self-efficacy. Similarly, Guidetti et al. (2018), in a study of Italian teachers, concluded that "self-efficacy totally mediates the impact of collective efficacy on perceived work ability" (p. 203). Also, in a SEM analysis of data from 642 Finnish teachers Malinen and Savolainen (2016) included both teacher self-efficacy and collective teacher efficacy as predictors of job satisfaction and burnout. They found that both teacher self-efficacy and collective efficacy correlated positively with job satisfaction and negatively with burnout. When controlled for teacher self-efficacy in a SEM analysis collective teacher efficacy was not significantly related to job satisfaction or to burnout. A possible interpretation of these findings is that it is the individual teacher's sense of self-efficacy that affects the teacher's motivation and well-being in the actual teaching situation. The findings may also be interpreted as an indication that perceived collective teacher efficacy affects teachers' personal self-efficacy and that the association between collective teacher efficacy and motivational and emotional responses are mediated through teacher self-efficacy (Stephanou \& Oikonomou, 2018). We therefore expected that collective teacher efficacy would correlate positively with engagement and belonging, but that collective efficacy would not be significantly related to engagement and belonging in a SEM analysis including individual teacher self-efficacy.

\subsection{Belonging}

Baumeister and Leary (1995) conceptualize the need to belong as a fundamental human motivation (Deci \& Ryan, 2000). The degree to which the need to belong is accommodated, for instance at the workplace, may affect motivation and commitment as well as well-being. At the student level, the feeling of belonging to the school or the school class correlates positively with motivation for schoolwork (Furrer \& Skinner, 2003; Goodenow \& Grady, 1993) and positive affect (McMahon, Parnes, Keys, \& Viola, 2008; Shochet, Dadds, Ham, \& Mantague, 2006). Skaalvik and Skaalvik (2011a; 2011b) also reported that teachers' feeling of belonging at the school where they were teaching were associated with higher 
levels of job satisfaction and lower levels of emotional exhaustion.

Roeser, Midgley, and Urdan (1996) perceive belonging as a feeling of relatedness and being valued. Similarly, Goodenow and Grady (1993) describe a sense of belonging as resulting from a feeling of being accepted, respected, and receiving social support from other members of the community. Hence, we expected positive and supportive relations with colleagues and the school administration to be positively associated with teachers' feeling of belonging. We also expected that value consonance would be associated with the feeling of belonging, because the sharing of values signals acceptance and respect. Supporting this expectation, previous research reveals a moderate to strong association between value consonance and teachers' feeling of belonging (Skaalvik \& Skaalvik, 2011b).

\subsection{Work Engagement}

Bandura (2006) emphasizes that self-efficacy is "the foundation of human motivation, well-being, and accomplishments" (p. 3). He maintains that "unless people believe they can produce desired effects by their actions they have little incentive to act or to persevere in the face of difficulties" (p. 3). Hence, self-efficacy beliefs are expected to influence people's goals and aspirations and their ability to motivate themselves. According to social cognitive theory, self-efficacy beliefs are also supposed to affect people's emotions. People of high self-efficacy are more likely to experience positive emotions like pride and happiness (Linnenbrink \& Pintrich, 2003). We therefore expect teacher self-efficacy to be positively related to measures of teacher motivation, for instance work engagement, which Schaufeli, Salanova, González-Romá, \& Bakker (2002) define as "a positive, fulfilling, work-related state of mind that is characterized by vigor, dedication, and absorption" (p. 74).

We have already shown that teacher self-efficacy is related to different measures of motivation and well-being, for instance, higher job satisfaction and lower levels of burnout. Also, Chesnut and Burley (2015), in a meta-analysis, found that teacher self-efficacy was associated with higher commitment, which they considered to be a form of motivation. Similar results are found by Gilbert et al. (2014), Klassen \& Chiu (2011) and Klassen et al. (2013). Empirical research exploring how self-efficacy and collective efficacy relate to engagement is scarce. Nevertheless, the available research reveals that teacher engagement is positively associated with teacher self-efficacy (Li, Wang, Gao, \& You, 2017; Simbula, Guglielmi, \& Schaufeli, 2011; Skaalvik \& Skaalvik, 2014).

A reasonable assumption is therefore that teacher self-efficacy, teachers' beliefs in their own abilities to produce desired outcomes, positively predicts teacher engagement. On the other hand, as discussed above, we do not expect collective teacher efficacy to be directly associated with the engagement of the individual teacher in the actual teaching situation. In the actual teaching situation, we suggest that a teacher's emotions and engagement result from her or his mastery expectations in that particular situation. 


\subsection{The Present Study}

The purpose of the present study was to explore relations between collective teacher efficacy and teacher self-efficacy and how these constructs were related to teachers' perceptions of job resources and job demands in the school environment, teachers feeling of belonging, and teacher engagement. The perceived job resources included in this study were: 1) positive and supportive relations with colleagues, 2) positive and supportive relations with the school principal, and 3) value consonance. These job resources were chosen because previous research shows these resources to be related to outcomes like self-efficacy, job satisfaction, teacher motivation, and teacher well-being (see above). The job demands included in the study were: 1) discipline problems, 2) time pressure, and 3) student diversity. These demands were included because previous research indicates that they are related to teacher stress and burnout (for an overview, see Skaalvik \& Skaalvik, 2017a; 2017c).

Based on our introductory analyses, we expected that collective teacher efficacy and teacher self-efficacy would be positively but moderately correlated. We also expected that both these constructs would correlate positively with all three job resources included in the study and negatively with the job demands. Based on the theoretical analysis and previous research we also expected that both teacher self-efficacy and collective teacher efficacy would correlate positively with belonging and engagement. However, previous studies also report that, when controlled for individual self-efficacy in SEM analyses, collective teacher efficacy was not significantly related to job satisfaction, teacher burnout, or work ability (see Section 2.3.). We therefore expected that, in a SEM analysis, engagement would be significantly related to individual self-efficacy but not to collective teacher efficacy.

As discussed above (Section 2.4.) we expected that positive relations with colleagues and with the school administration as well as value consonance would be positively associated with teachers feeling of belonging. We also expected positive relations with colleagues and with the school administration as well as value consonance to be positively associated with engagement. In the SEM model, we did not expect any direct relations between the job demands and engagement or belonging. We expected that possible relations with engagement would be mediated through self-efficacy. The expectations outlined above are visualized in Figure 1.

\section{Method}

\subsection{Participants and Procedure}

Seven hundred and sixty teachers in elementary school (grade $1-7$ ) and middle school (grade 8 - 10) participated in this study. The study was part of a larger survey and analysis of relations between teachers' perception of the school goal structure, teacher self-efficacy, and job satisfaction are presented separately (Skaalvik \& Skaalvik, 2017b). The data were collected in April and May of 2016. 


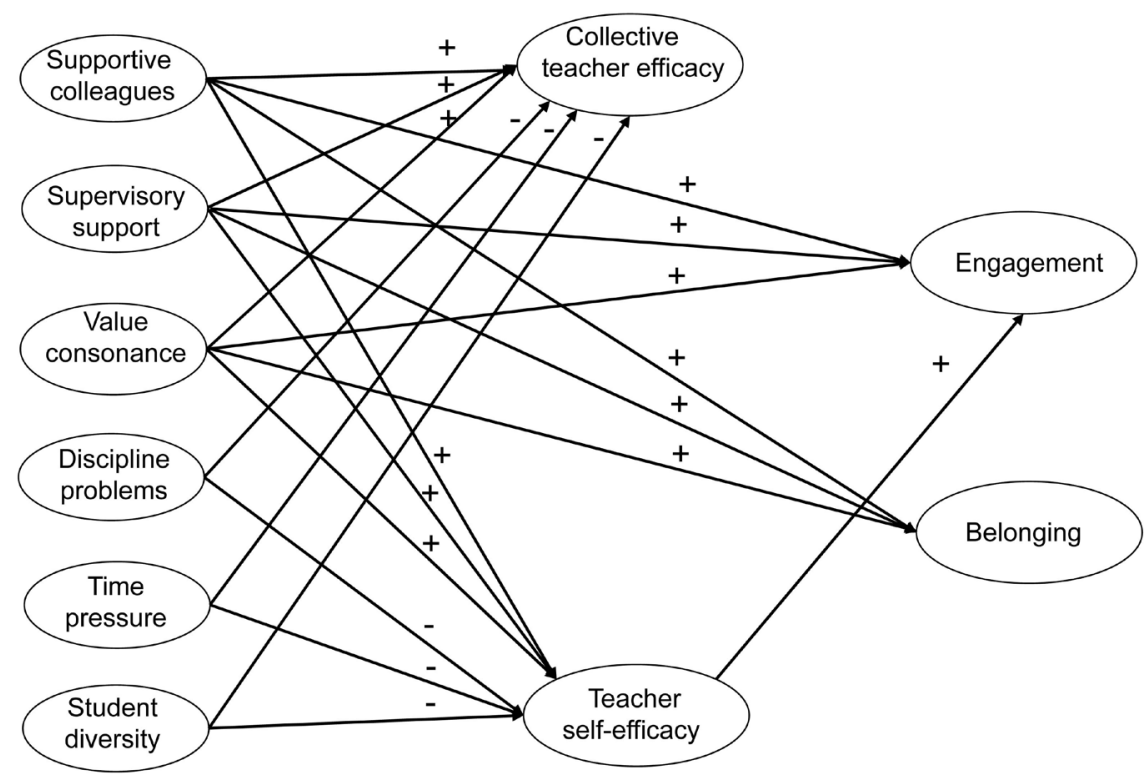

Figure 1. Theoretical model of relations between the study variables.

Twenty-two schools were drawn at random from three counties in central Norway, and all teachers in these schools were invited to participate. Eighty-one percent of the teachers at the selected schools participated in the study. The teachers were informed that participation was voluntary. A particular period of time during working hours was set aside for all teachers to fill out the questionnaire at the same time. When the questionnaires were filled out, they were put in envelopes and sealed on the spot to assure the teachers that they were anonymous. Sixty-nine percent of the participants were women. The participants' ages ranged from 23 to 68 years with a mean of 44 years, and their experience as teachers ranged from 1 to 47 years with a mean of 15 years.

\subsection{Instruments}

\subsubsection{Job Resources}

Both the perception of "supportive colleagues" and "supervisory support" were measured as a combination of instrumental and emotional support. Supportive colleagues were measured by means of a three-item scale developed by Skaalvik and Skaalvik (2011a): "In educational matters, I can always get good help from my colleagues", "The relations among the colleagues at this school are characterized by friendliness and a concern for each other", and "Teachers at this school help and support each other”. Cronbach's alpha was .84. Supervisory support was also measured with a previously tested three-item scale (Skaalvik \& Skaalvik, 2011a). The items were: "In educational matters, I can always get help and advice from the school leadership", "My relationship with the school leadership is one of mutual trust and respect", and "The school leadership is supportive and praises good work". Cronbach's alpha was .86. Value consonance was measured by means of a previously tested three-item "Value consonance scale" (Skaalvik \& Skaalvik, 2011a). The items were: "My educational values are in accordance with 
the values which are emphasized at this school", "My colleagues and I have the same opinion about what is important in education", and "I feel that this school shares my view of what constitutes good teaching". Cronbach's alpha for the scale was .80. Responses on all items measuring job resources were given on a 6-point scale from "Completely disagree" (1) to "Completely agree" (6).

\subsubsection{Job Demands}

We included three measures of job demands in the study: 1) discipline problems, 2) time pressure, and 3) student diversity. These variables are previously tested by five, three, and three items, respectively (Skaalvik \& Skaalvik, 2016). The items measuring discipline problems were: "My teaching is often disrupted by students who lack discipline", "Some students with behavior problems make it difficult to carry out lessons as planned", and "Controlling students' behavior takes a lot of time and effort". Responses were given on a 6-point scale from "Completely disagree" (1) to "Completely agree" (6). Cronbach's alpha for the scale was .83. Examples of items measuring time pressure are: "Preparation for teaching must often be done after working hours", "Life at school is hectic and there is no time for rest and recovery", and "Meetings, administrative work, and documentation take much of the time that should be used for preparing to teach". Responses were given on a 5-point scale from "Completely disagree" (1) to "Completely agree" (5). Cronbach's alpha for the scale was .83. The items measuring student diversity were: "In my classes there are large variations in students' abilities," "In my classes there are large variations in students' needs," and "In my classes there is a huge difference between the best and the poorest students." Responses were given on a 6-point scale from "Completely disagree" (1) to "Completely agree" (6). Cronbach's alpha for the scale was .90 .

\subsubsection{Collective Teacher Efficacy}

Collective teacher efficacy was measured by the five-item Perceived Collective Teacher Efficacy scale (Skaalvik \& Skaalvik, 2007). The Scale measured collective efficacy related to instruction, motivating students, controlling student behaviour, addressing students' needs, and creating a safe environment at school. In order to distinguish collective efficacy from self-efficacy, all collective efficacy items focused on what "we" or "teachers at this school" were able to do. An example of an item is: "As teachers of this school we can get even the most difficult students engaged in their schoolwork." Responses were given on a 5-point scale from "False" (1) to "True" (5). Cronbach's alpha for the scale was .80.

\subsubsection{Teacher Self-Efficacy}

Teacher self-efficacy was measured by the 24-item Norwegian Teacher Self-Efficacy Scale (Skaalvik \& Skaalvik, 2007; 2010). The scale measures six dimensions of teacher self-efficacy: instruction, adapting education to individual students' needs, motivating students, keeping discipline, cooperating with colleagues and parents, and coping with changes and challenges. An example of an item is 
"How certain are you that you can wake the desire to learn even among the lowest achieving students?" (motivating students). Responses are given on a 7-point scale from "Not certain at all" (1) to "Absolutely certain" (7). The scale shows good validity both in Norway and Italy (Avanzi et al., 2013). Cronbach's alpha for the scale was .90 .

\subsubsection{Belonging}

Feeling of belonging was measured by means of a previously tested three-item Feeling of belonging scale (Skaalvik \& Skaalvik, 2011a). The items were: "I feel that I belong at this school", "I feel that I am accepted by the leadership at this school", and "I feel that my colleagues have faith in me". Responses were given on a 5-point scale from "False" (1) to "True" (5). Cronbach's alpha for the scale was 88 .

\subsubsection{Engagement}

We measured engagement for teaching by means of the short nine-item version of the Utrecht Work Engagement Scale (Schaufeli, Bakker, \& Salanova, 2006). The scale measures three dimensions of engagement: vigor, dedication, and absorption. An example of an item is: "At my work, I feel bursting with energy" (vigor). Responses were given on a 7-point scale from "Never" (1) to "Every day" (7). Cronbach's alpha for the scale was .88.

\subsection{Data Analyses}

The data were analyzed by means of zero order correlations, confirmatory factor analysis, and SEM analysis using the AMOS 25 program. We first tested a measurement model by means of confirmatory factor analyses. Based on the factor analysis we conducted SEM analyses with job resources and job demands as six correlated endogenous primary factors. We used well-established indices of model fit: CFI, IFI, TLI, and RMSEA. For the CFI, IFI, and TLI indices, values greater than .90 are considered acceptable, and values greater than .95 indicate a good fit to the data (Bollen, 1989; Byrne, 2001; Hu \& Bentler, 1999). For well-specified models, an RMSEA of .06 or less reflects a good fit (Hu \& Bentler, 1999). Missing values were treated based on maximum likelihood (ML) estimation in the AMOS program (Byrne, 2001). Compared to both listwise and pairwise deletion of missing data and to mean imputation, ML estimation will exhibit the least bias (Little \& Rubin, 1989; Muthén, Kaplan, \& Hollis, 1987; Schafer, 1997).

\section{Results}

\subsection{Zero Order Correlations}

Zero order correlations between the study variables as well as statistical means and standard deviations are shown in Table 1. The three job resources (supportive colleagues, supervisory support, and value consonance) were positively correlated (between $r .=.53$ and .59 ). The three job demands (discipline problems, time pressure, and student diversity) were also positively, but weakly correlated 
Table 1. Zero order correlations among the study variables and descriptive statistics.

\begin{tabular}{|c|c|c|c|c|c|c|c|c|c|c|}
\hline Study Variables & 1 & 2 & 3 & 4 & 5 & 6 & 7 & 8 & 9 & 10 \\
\hline 1) Supportive colleagues & - & .53 & .56 & -.03 & -.12 & .06 & .44 & .40 & .23 & .26 \\
\hline 2) Supervisory support & & - & .59 & -.06 & -.25 & -.02 & .50 & .45 & .26 & .23 \\
\hline 3) Value consonance & & & - & -.06 & -.16 & .03 & .47 & .49 & .26 & .31 \\
\hline 4) Discipline problems & & & & - & 19 & .19 & -.08 & -.12 & -.14 & -.07 \\
\hline 5) Time pressure & & & & & - & .18 & -.16 & -.12 & -.14 & -.14 \\
\hline 6) Student diversity & & & & & & - & .03 & -.02 & -.08 & -.02 \\
\hline 7) Collective efficacy & & & & & & & - & .24 & .41 & .26 \\
\hline 8) Belonging & & & & & & & & - & .15 & .36 \\
\hline 9) Teacher self-efficacy & & & & & & & & & - & .38 \\
\hline 10) Engagement & & & & & & & & & & - \\
\hline Mean & 16.03 & 14.60 & 14.49 & 10.16 & 20.70 & 15.74 & 22.92 & 15.54 & 121.34 & 51.24 \\
\hline Standard Deviation & 2.01 & 3.09 & 2.14 & 3.80 & 3.03 & 2.70 & 3.19 & 2.74 & 13.49 & 7.83 \\
\hline
\end{tabular}

Note: Correlations $>.07$ are significant at $p<.05$ level and correlations $>.10$ are significant at $p<.01$ level.

(between $r .=.18$ and .19 ). The correlations between the job resource variables and two of the job demand variables (discipline problems and student diversity) were weak and nonsignificant. However, time pressure correlated significantly with all job resources. These correlations were weak and negative (between $r$. $=$ -.12 and -.25 ).

As expected, collective teacher efficacy and teacher self-efficacy were moderately correlated $(r .=.41)$. Both collective teacher efficacy and teacher self-efficacy were positively related to the job resources. The correlations with collective efficacy ranged from $r .=.44$ to .50 whereas the correlations with self-efficacy were weaker and ranged from $r .=.23$ to .26 . With one exception both collective teacher efficacy and teacher self-efficacy correlated significantly and negatively, but weakly with the job demands.

The teachers' feeling of belonging correlated positively with the job resources (ranging from $r .=.40$ to .49$)$ as well as with collective efficacy $(r .=.24)$ and teacher self-efficacy $(r=.15)$. Engagement correlated positively with all job resources (ranging from $r .=.23$ to .31 ) as well as with collective efficacy $(r=.26)$, self-efficacy $(r=.38)$, and belonging $(r=.36)$. Engagement was significantly but weakly related to only one of the job demand variables-the correlation with time pressure was $r=-.14$.

\subsection{Confirmatory Factor Analyses}

We tested a measurement model by means of confirmatory factor analyses. The model consisted of 10 primary factors: the three job demands, the three job resources, collective teacher efficacy, teacher self-efficacy, belonging and engagement. The model had acceptable fit to the data $\left(\chi^{2}(728, N=760)=1930.973, p\right.$ 
$<.001$, RMSEA $=.047$, IFI $=.918$, CFI $=.917$, TLI $=.902)$. All factor loadings (standardized regression coefficients) were strong and varied from .55 to .96 (Table 2). The correlations among the latent variables (Table 3 ) were quite similar to the zero order correlations and indicated that there would be no serious collinearity problems connected to the SEM analysis. The correlation between the latent collective efficacy and self-efficacy factors was . 50 .

Table 2. Confirmatory factor analysis-factor loadings.

\begin{tabular}{|c|c|c|c|c|c|c|c|c|c|c|}
\hline Scales & 1 & 2 & 3 & 4 & 5 & 6 & 7 & 8 & 9 & 10 \\
\hline $\begin{array}{l}\text { Supportive } \\
\text { colleagues }\end{array}$ & $\begin{array}{l}.64 \\
.88 \\
.88\end{array}$ & & & & & & & & & \\
\hline $\begin{array}{l}\text { Supervisory } \\
\text { support }\end{array}$ & & $\begin{array}{l}.84 \\
.87 \\
.87\end{array}$ & & & & & & & & \\
\hline $\begin{array}{c}\text { Value } \\
\text { consonance }\end{array}$ & & & $\begin{array}{l}.70 \\
.92 \\
.96\end{array}$ & & & & & & & \\
\hline $\begin{array}{l}\text { Discipline } \\
\text { problems }\end{array}$ & & & & $\begin{array}{l}.71 \\
.73 \\
.74\end{array}$ & & & & & & \\
\hline $\begin{array}{c}\text { Time } \\
\text { pressure }\end{array}$ & & & & & $\begin{array}{l}.62 \\
.63 \\
.64 \\
.67 \\
.74\end{array}$ & & & & & \\
\hline $\begin{array}{l}\text { Student } \\
\text { diversity }\end{array}$ & & & & & & $\begin{array}{l}.74 \\
.88 \\
.88\end{array}$ & & & & \\
\hline $\begin{array}{l}\text { Collective } \\
\text { efficacy }\end{array}$ & & & & & & & $\begin{array}{l}.55 \\
.63 \\
.64 \\
.73 \\
.75\end{array}$ & & & \\
\hline Belonging & & & & & & & & $\begin{array}{l}.57 \\
.83 \\
.91\end{array}$ & & \\
\hline Self-efficacy & & & & & & & & & $\begin{array}{l}.50 \\
.51 \\
.59 \\
.60 \\
.70 \\
.73\end{array}$ & \\
\hline Engagement & & & & & & & & & & $\begin{array}{l}.56 \\
.57 \\
.64 \\
.65 \\
.69 \\
.73 \\
.75 \\
.81 \\
.81\end{array}$ \\
\hline
\end{tabular}


Table 3. Confirmatory factor analysis-correlations among the latent variables.

\begin{tabular}{|c|c|c|c|c|c|c|c|c|c|c|}
\hline Study Variables & 1 & 2 & 3 & 4 & 5 & 6 & 7 & 8 & 9 & 10 \\
\hline 1) Supportive colleagues & - & .58 & .54 & -.03 & -.12 & .07 & .52 & .48 & .24 & .29 \\
\hline 2) Supervisory support & & - & .63 & -.07 & -.28 & -.02 & .59 & .51 & .27 & .26 \\
\hline 3) Value consonance & & & - & -.09 & -.19 & .03 & .51 & .52 & .28 & .33 \\
\hline 4) Discipline problems & & & & - & .27 & .24 & -.10 & -.13 & -.17 & -.14 \\
\hline 5) Time pressure & & & & & - & .22 & -.19 & -.13 & -.18 & -.19 \\
\hline 6) Student diversity & & & & & & - & .03 & .00 & -.13 & -.02 \\
\hline 7) Collective efficacy & & & & & & & - & .31 & .50 & .30 \\
\hline 8) Belonging & & & & & & & & - & .17 & .43 \\
\hline 9) Teacher self-efficacy & & & & & & & & & - & .39 \\
\hline 10) Engagement & & & & & & & & & & - \\
\hline
\end{tabular}

\subsection{SEM Analyses}

The relations between the variables were further analyzed by means of SEM analysis for latent variables. We first tested the theoretical model presented in Figure 1 (Model A). To test if there were any significant, but unexpected relations between the variables, we started with a full model and deleted nonsignificant paths one by one based on the regression coefficients. This procedure led to the inclusion of two small, but unexpected negative paths: one from time pressure to engagement and one from collective efficacy to belonging. The final empirical model, showing standardized regression coefficients, is displayed in Figure 2. The model has acceptable fit to the data $\left(\chi^{2}(744, N=760)=2082.002\right.$, $p<.001, \mathrm{RMSEA}=.049$, IFI $=.909$, CFI $=.908$, TLI $=.894)$.

Figure 2 shows that all job resources that we included in the study were positively associated with collective teacher efficacy (beta values ranging from .19 to .35). The strongest association with collective efficacy was found for supervisory support. All job resources were also positively associated with teachers' feeling of belonging (betas ranging from .20 to .32). Moreover, value consonance was positively associated with individual teacher self-efficacy $($ beta $=.28)$ and both value consonance and supportive colleagues were associated with engagement (beta values $=.18$ and .12 , respectively).

We found few and small associations with the job demands included in the study. Both discipline problems and student diversity were negatively associated with teacher self-efficacy (beta values $=-.14$ and -.10 ) and time pressure was negatively associated with engagement (beta $=-.09$ ). In the SEM model none of the job demands were significantly related to collective efficacy or to the feeling of belonging.

As expected, teacher self-efficacy was positively associated with engagement (beta $=.30$ ), but not with belonging. Collective teacher efficacy was in the SEM model not significantly associated with engagement. 


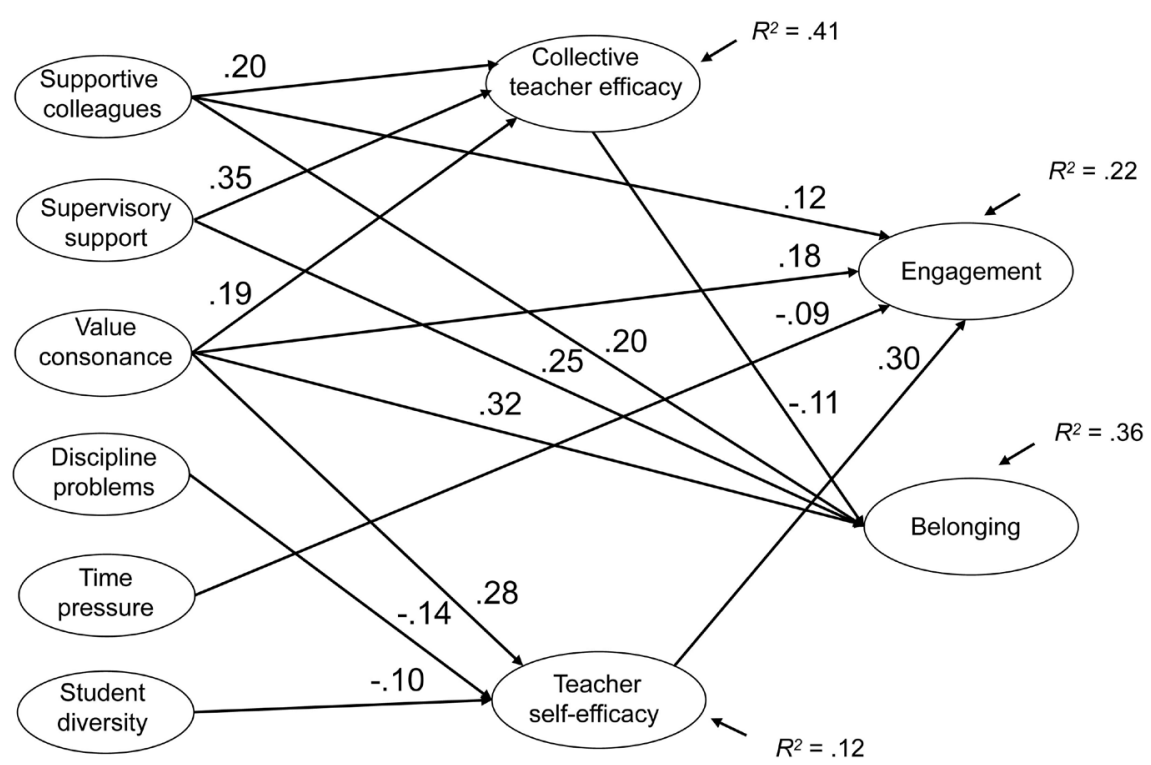

Figure 2. Structural model A of relations between job demands, job resources, collective teacher efficacy, teacher self-efficacy, feeling of belonging, and teacher engagement.

The SEM analysis revealed several indirect associations. All job resources were indirectly related to belonging, mediated through collective teacher efficacy. Also, value consonance and two of the job demands, time pressure and student diversity, were indirectly associated with engagement, mediated through teacher self-efficacy.

Because 1) collective efficacy and self-efficacy in the factor analysis correlated $.50,2)$ both collective efficacy and self-efficacy correlated positively with engagement ( $r=.26$ and .38 ), and 3 ) collective efficacy was not significantly associated with engagement in the SEM analysis of Model A, a possible interpretation was that the association between collective efficacy and engagement was mediated through teacher self-efficacy. Because collective efficacy in Model A was not significantly associated with engagement, collective efficacy could not mediate the association between self-efficacy and engagement. We therefore tested a second SEM model (Model B) including a path from collective efficacy to self-efficacy (model B). The model, which is shown in Figure 3, had acceptable fit to the data $\left(\chi^{2}(743, N=760)=2000.224, p<.001\right.$, RMSEA $=.047$, $\mathrm{IFI}=.914, \mathrm{CFI}=.914, \mathrm{TLI}=.900)$. In this model the association between value consonance and self-efficacy was mediated through collective efficacy. Moreover, collective efficacy was indirectly related to engagement, mediated through teacher self-efficacy.

\section{Discussion}

Structural model A (Figure 2) confirmed that all job resources that were included in this study were positive and independent predictors of both collective teacher efficacy and teachers' feeling of belonging. In the model, the positive associations between job resources and belonging were direct and not mediated 


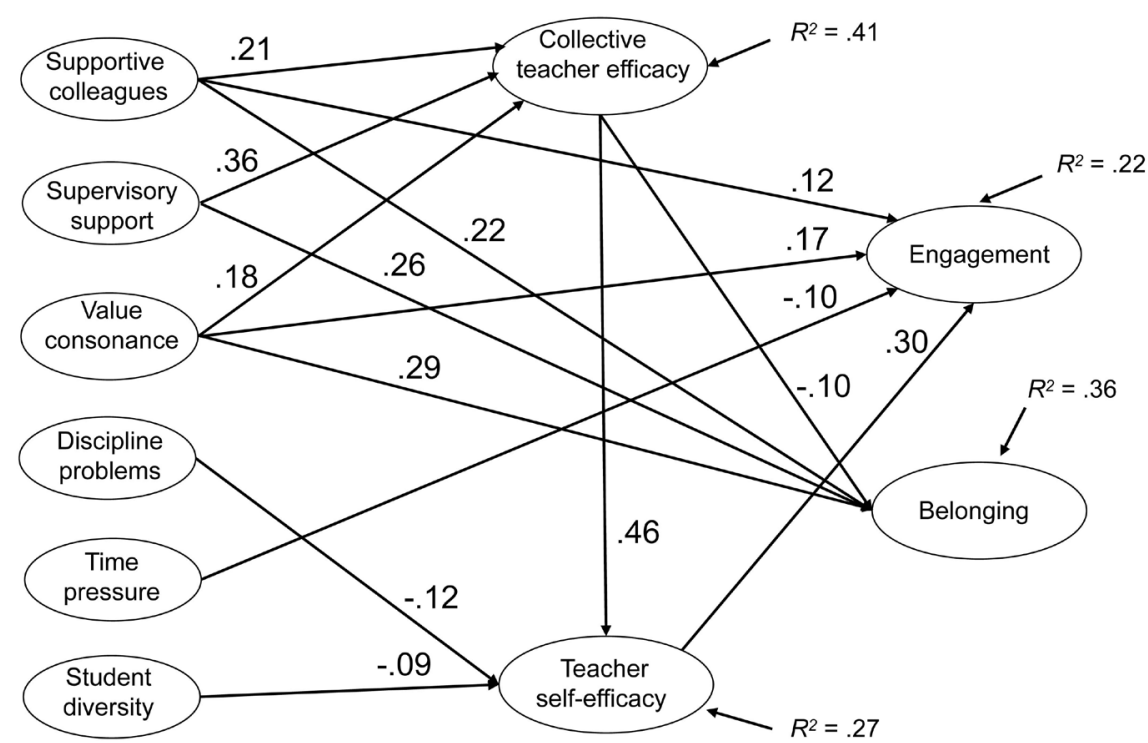

Figure 3. Structural model B of relations between job demands, job resources, collective teacher efficacy, teacher self-efficacy, feeling of belonging, and teacher engagement.

through collective efficacy. Furthermore, in the SEM analysis only one of the job resources, value consonance, was significantly associated with teacher self-efficacy. Teacher self-efficacy was positively associated with engagement but not with belonging, whereas collective teacher efficacy was not positively associated with either engagement or belonging. In structural model B (Figure 3) we included a path from collective efficacy to self-efficacy. This resulted in two major changes. This model revealed no direct association between value consonance and self-efficacy. In this model, the association between value consonance and self-efficacy was mediated through collective efficacy. Secondly, in this model, collective efficacy was indirectly related to engagement, mediated through teacher self-efficacy.

Taken together, the SEM analyses indicate that it is the individual teacher's sense of self-efficacy related to his or her own teaching that affects the teacher's engagement in the actual teaching situation. Although teachers collaborate, work in teams, and may support each other both emotionally and instrumentally, in the actual teaching situation the teachers are primarily alone and must trust their own skills and abilities. Their engagement will therefore be influenced by their self-efficacy beliefs-their beliefs in what they are able to accomplish through their own teaching and classroom management. We propose that a reasonable interpretation of these findings is that the teachers' self-efficacy beliefs are affected by collective teacher efficacy beliefs, which mediate the association between job resources at school and teacher self-efficacy. This interpretation is supported by previous findings referred in the introduction (Malinen \& Savolainen, 2016; Skaalvik \& Skaalvik, 2007; Stephanou \& Oikonomou, 2018) but should be tested in longitudinal studies.

It is important to note that the job resources included in this study were rela- 
tional and value-oriented (positive and supportive relations with colleagues and the school leadership as well as value consonance). Hence, the findings indicate that these particular type of job resources are more strongly related to collective efficacy than to self-efficacy, and that the associations between these job resources and self-efficacy are mediated through collective efficacy. As noted by Guidetti et al. (2018) collective teacher efficacy refers to the teachers' beliefs about what the school can accomplish. Similarly, Klassen (2010) conceptualize collective teacher efficacy as teachers' judgments of the capabilities of the staff or school to which they belong (see Section 2.2.). Therefore, as discussed above, in a collaborative and supportive collegial environment the observation of successful colleagues may enhance collective efficacy. Other job resources may be directly associated with teacher self-efficacy. This may be true for job resources that facilitate the teaching process and make it easier to achieve the teaching goals, for instance adequate learning aids, good textbooks, resourceful students, and supportive parents.

Both SEM analyses revealed that all job resources included in this study were directly associated with the teachers' feeling of belonging. We suggest that the positive associations between the job resources and teachers feeling of belonging also may be explained by our choice of job resources in this study. Experiencing supportive colleagues and a supportive school administration will likely increase the feeling of belonging. The same may be true for the experience of sharing educational values with one's colleagues. This interpretation is in accordance with Goodenow's (1993) conceptualization, in which belonging requires the experience of being liked, respected, and valued.

Previous research has shown strong associations between job demands and teacher burnout, particularly between the time pressure, but also discipline problems, and the emotional exhaustion dimension of burnout (for an overview, see Skaalvik \& Skaalvik, 2017a). In contrast, the present study shows only a small negative association between time pressure and engagement and also that discipline problems and student diversity were weakly related to teacher self-efficacy. A possible interpretation is that these job demands, particularly time pressure, affect teacher burnout and well-being negatively, but that they have little effect on collective efficacy, self-efficacy, and the feeling of belonging. As for teacher burnout, previous research shows that the impact of job demands is stronger than the impact of job resources (e.g., Hakanen et al., 2006). Thus, a hypothesis for future research may be that the job resources in the teaching profession have their primary effect on teacher efficacy and motivation whereas the job demands have their primary effect of teacher burnout and well-being. An important issue for future research may therefore be to explore possible long term mutual relations between 1) teacher self-efficacy and motivation and 2) teacher burnout and well-being. The JD-R model actually proposes an interaction between a motivational and a health impairment process.

An interesting finding is that, in the SEM models, we found a negative association between collective teacher efficacy and belonging. A reasonable assump- 
tion would be that collective efficacy beliefs would increase the teachers' feeling of belonging. Also, the zero-order correlation between these constructs was positive $(r .=.24)$. However, when controlled for job resources, the SEM analyses showed a small negative, but close to zero association between collective efficacy and belonging. We can only speculate about this finding. A possible explanation, that needs to be tested in future research, is that collective efficacy contains an element of social comparison. For instance, a teacher who experiences the collective capabilities of the teacher collegium to be at a certain level may perceive her or his personal capability to be at the same level, at a lower level, or at a higher level. Thus, based on social comparison teachers may perceive different degrees of discrepancy between their own capability and the capabilities of the collegium. The perception of a large discrepancy resembles Rosenberg's (1977) description of a dissonance context (see Section 2.1.). We, therefore, suggest that teachers who perceive large discrepancies will develop lower feelings of belonging than teachers who perceive small or nonexistent discrepancies. Therefore, high collective efficacy beliefs may result in a strong feeling of belonging for some teachers but a lower feeling of belonging for other teachers. We suggest that these processes equal each other out resulting in a close to zero association between perceived collective efficacy and feeling of belonging when the effect of the job resources are controlled for in the SEM analyses. However, we should note that this is merely a speculation that needs to be tested in future research.

An interesting finding was also that teachers' engagement and feeling of belonging was only moderately correlated $(r .=.36)$. Moreover, whereas belonging in the SEM analysis was moderately and directly associated with all job resources, engagement was weakly associated with supportive colleagues and value consonance and not significantly associated with supervisory support. A possible interpretation may be that teachers' feeling of belonging primarily is a result of the social environment, including value consonance, whereas teacher engagement is more strongly related to self-efficacy beliefs in the actual teaching situation.

In this study, collective efficacy was analyzed at the individual level, as each teacher's judgments of the conjoint capabilities of the staff at the school. Teachers at the same school may perceive the conjoint capabilities differently, and we believe that it is the individual teacher's belief about the capabilities of the staff that may affect her or his experiences and functioning. Nevertheless, an interesting task for future research may be to test these variables at the school level.

This study has both theoretical and practical implications. Theoretically, it extends our understanding of how collective teacher efficacy and teacher self-efficacy are related to the work environment at school as well as to teacher engagement. It indicates that positive and supportive social relations, as well as a common understanding of goals and values, are important job resources that may enhance collective teacher efficacy as well as teachers feeling of belonging. Thus, the analyses underscore the significance of value consonance in the teaching profession. In both SEM models, this construct was positively associated 
with collective teacher efficacy as well as with engagement and belonging. Therefore, an important issue in teacher education should be to make students reflect on educational goals and values. Moreover, an important task for the leadership at any school should be to work to develop a common understanding of educational goals and values among the staff.

This study has several limitations. We only explored three job resources and three job demands. Although previous research suggests that these resources and demands are particularly important, future research should include alternative resources and demands. It is particularly important to explore if job resources that are less tied to supportive social environments and common values provide results that are similar to the findings in this study. We should also emphasize that this study was designed as a cross-sectional one, and that longitudinal studies are needed to explore causal relations.

\section{Conclusion}

The job resources included in this study were positively associated with both collective teacher efficacy and teachers' feeling of belonging. We suggest that these associations may be explained by our choice of job resources, as we included relational and value-oriented job resources in the study. The result of the SEM analyses indicated that collective teacher efficacy mediated the association between the job resources and teacher self-efficacy, whereas teacher self-efficacy mediated the association between collective teacher efficacy and engagement. We suggest that although teachers collaborate, work in teams, and may support each other both emotionally and instrumentally, in the actual teaching situation the teachers are primarily alone and must trust their own skills and abilities. Their engagement will therefore be influenced by their self-efficacy beliefs-their beliefs in what they are able to accomplish through their own teaching and classroom management. Although previous research shows that job demands like time pressure and discipline problems are associated with teacher stress and burnout, this study indicates that these type of job demands have a negligible impact on teacher self-efficacy and motivation.

\section{Acknowledgements}

This research was supported by a grant from the Union of Education Norway

\section{Role of the Funding Source}

This research was supported by a grant from the Union of Education Norway. The authors had full access to all the data in this study and take complete responsibility for the integrity of the data and the accuracy of the data analysis.

\section{Conflicts of Interest}

The authors declare that they have no conflict of interest. The study was conducted in line with the ethical research guidelines and approved by the Norwe- 
gian Centre for Research Data (NSD) which serves as a national ethical research committee.

\section{References}

Adams, C. M., \& Forsyth, P. B. (2006). Proximate Sources of Collective Teacher Efficacy. Journal of Educational Administration, 44, 625-642. https://doi.org/10.1108/09578230610704828

Aldridge, J. M., \& Fraser, B. J. (2016). Teachers' Views of Their School Climate and Its Relationship with Teacher Self-Efficacy and Job Satisfaction. Learning Environments Research, 19, 291-307. https://doi.org/10.1007/s10984-015-9198-x

Aloe, A. M., Amo, L. C., \& Shanahan, M. E. (2014). Classroom Management Self-Efficacy and Burnout: A Multivariate Meta-Analysis. Educational Psychology Review, 26, 101-126. https://doi.org/10.1007/s10648-013-9244-0

Avanzi, L., Miglioretti, M., Velasco, V., Balducci, C., Vecchio, L., Fraccaroli, F., \& Skaalvik, E. M. (2013). Cross-Validation of the Norwegian Teacher's Self-Efficacy Scale (NTSES). Teaching and Teacher Education, 31, 69-78. https://doi.org/10.1016/j.tate.2013.01.002

Avanzi, L., Schuh, S. C., Fraccaroli, F., \& van Dick, R. (2015). Why Does Organizational Identification Relate to Reduced Employee Burnout? The Mediating Influence of Social Support and Collective Efficacy. Work \& Stress, 29, 1-10. https://doi.org/10.1080/02678373.2015.1004225

Bakker, A. B., \& Demerouti, E. (2006). The Job Demands-Resources Model: State of the Art. Journal of Managerial Psychology, 22, 309-328. https://doi.org/10.1108/02683940710733115

Bakker, A. B., \& Demerouti, E. (2014). Job Demands-Resources Theory. In P. Y. Chen, \& C. L. Cooper (Eds.), Wellbeing: A Complete Reference Guide, Work and Wellbeing (Vol. 3, pp.37-64). Chichester: Wiley-Blackwell. https://doi.org/10.1002/9781118539415.wbwell019

Bandura, A. (1977). Self-Efficacy: Toward a Unifying Theory of Behavioral Change. Psychological Review, 84, 191-215. https://doi.org/10.1037/0033-295X.84.2.191

Bandura, A. (1997). Self-Efficacy: The Exercise of Control. New York: Freeman.

Bandura, A. (2006). Adolescent Development from an Agentic Perspective. In F. Pajares, \& T. Urdan (Eds.), Self-Efficacy Beliefs of Adolescents (pp. 1-43). Greenwich, CT: Information Age Publishing.

Baumeister, R. F., \& Leary, M. R. (1995). The Need to Belong: Desire for Interpersonal Attachments as a Fundamental Human Motivation. Psychological Bulletin, 117, 497-529. https://doi.org/10.1037/0033-2909.117.3.497

Betoret, F. D., \& Artiga, A. G. (2010). Barriers Perceived by Teachers at Work, Coping Strategies, Self-Efficacy and Burnout. The Spanish Journal of Psychology, 13, 637-654. https://doi.org/10.1017/S1138741600002316

Bollen, K. A. (1989). A New Incremental Fit Index for General Structural Models. Sociological Methods \& Research, 17, 303-316. https://doi.org/10.1177/0049124189017003004

Brouwers, A., \& Tomic, W. (2000). A Longitudinal Study of Teacher Burnout and Perceived Self-Efficacy in Classroom Management. Teaching and Teacher Education, 16, 239-253. https://doi.org/10.1016/S0742-051X(99)00057-8

Byrne, B. M. (2001). Structural Equation Modelling with AMOS. Basic Concepts, Applications, and Programming. Mahwah, NJ: Lawrence Erlbaum Ass. 
Capa Aydin, T., \& Woolfolk Hoy, A. (2005). What Predicts Teacher Self-Efficacy? Academic Exchange Quarterly, 9, 123-128.

Caprara, G. V., Barbaranelli, L., Borgogni, L., \& Steca, P. (2003). Efficacy Beliefs as Determinants of Teacher's Job Satisfaction. Journal of Educational Psychology, 95, 821-832. https://doi.org/10.1037/0022-0663.95.4.821

Caprara, G. V., Barbaranelli, L., Borgogni, L., Petitta, L., \& Rubinacci, A. (2003). Teachers', School Staff's, and Parents' Efficacy Beliefs as Determinants of Attitudes toward School. European Journal of Psychology of Education, 18, 15-31. https://doi.org/10.1007/BF03173601

Chesnut, S. R., \& Burley, H. (2015). Self-Efficacy as a Predictor of Commitment to the Teaching Profession: A Meta-Analysis. Educational Research Review, 15, 1-16. https://doi.org/10.1016/j.edurev.2015.02.001

Collie, R. J., Shapka, J. D., \& Perry, N. E. (2012). School Climate and Social-Emotional Learning: Predicting Teacher Stress, Job Satisfaction, and Teaching Efficacy. Journal of Educational Psychology, 104, 1189-1204. https://doi.org/10.1037/a0029356

Deci, E. L., \& Ryan, R. M. (2000). The "What" and "Why" of Goal Pursuits. Human Needs and the Self-Determination of Behavior. Psychological Inquiry, 11, 227-268. https://doi.org/10.1207/S15327965PLI1104_01

Demerouti, E., Bakker, A. B., Nachreiner, F., \& Schaufeli, W. B. (2001). The Job Demands-Resources Model of burnout. Journal of Applied Psychology, 86, 499-512. https://doi.org/10.1037/0021-9010.86.3.499

Fernet, C., Guay, F., Senécal, C., \& Austin, S. (2012). Predicting Intraindividual Changes in Teacher Burnout: The Role of Perceived School Environment and Motivational Factors. Teaching and Teacher Education, 28, 514-525. https://doi.org/10.1016/j.tate.2011.11.013

Friedman, I. A. (1995). Student Behavior Patterns Contributing to Teacher Burnout. The Journal of Educational Research, 88, 281-289. https://doi.org/10.1080/00220671.1995.9941312

Furrer, C., \& Skinner, E. A. (2003). Sense of Relatedness as a Factor in Children's Academic Engagement and Performance. Journal of Educational Psychology, 95, 148-162. https://doi.org/10.1037/0022-0663.95.1.148

Gilbert, R. B., Adesope, O. O., \& Schroeder, N. L. (2014). Efficacy Beliefs, Job Satisfaction, Stress and Their Influence on the Occupational Commitment of English-Medium Content Teachers in the Dominican Republic. Educational Psychology, 34, 876-899. https://doi.org/10.1080/01443410.2013.814193

Goddard, R. D., Hoy, W. K., \& Hoy, A. W. (2004). Collective Efficacy Beliefs: Theoretical Developments, Empirical Evidence, and Future Directions. Educational Researcher, 33, 3-13. https://doi.org/10.3102/0013189X033003003

Goodenow, C (1933). Classroom Belonging among Early Adolescent Students. The Journal of Early Adolescence, 13, 21-43. https://doi.org/10.1177/0272431693013001002

Goodenow, C., \& Grady, K. E. (1993). The Relationship of School Belonging and Friends' Values to Academic Motivation among Urban Adolescent Students. The Journal of Experimental Education, 62, 60-71. https://doi.org/10.1080/00220973.1993.9943831

Guidetti, G., Viotti, S., Bruno, A., \& Converso, D. (2018). Teachers' Work Ability: A Study of Relationships between Collective Efficacy and Self-Efficacy Beliefs. Psychology Research and Behavior Management, 11, 197-206. https://doi.org/10.2147/PRBM.S157850

Hakanen, J. J., Bakker, A. B., \& Schaufeli, W. B. (2006). Burnout and Work Engagement 
among Teachers. Journal of School Psychology, 43, 495-513.

https://doi.org/10.1016/j.jsp.2005.11.001

Hu, L. T., \& Bentler, P. M. (1999). Cutoff Criteria for Fit Indexes in Covariance Structure Analysis: Conventional Criteria versus New Alternatives. Structural Equation Modeling: A Multidisciplinary Journal, 6, 1-55. https://doi.org/10.1080/10705519909540118

Klassen, R. M. (2010). Teacher Stress: The Mediating Role of Collective Efficacy Beliefs. The Journal of Educational Research, 103, 342-350. https://doi.org/10.1080/00220670903383069

Klassen, R. M., Bong, M, Usher, E. L., Chong, W. H., Huan, V. S., Wong, I. Y. F., \& Georgiou, T. (2009). Exploring the Validity of a Teachers' Self-Efficacy Scale in Five Countries. Contemporary Educational Psychology, 34, 67-76.

https://doi.org/10.1016/j.cedpsych.2008.08.001

Klassen, R. M., Usher, E. L., \& Bong M. (2010). Teachers' Collective Efficacy, Job Satisfaction, and Job Stress in Cross-Cultural Context. The Journal of Experimental Education, 78, 464-486. https://doi.org/10.1080/00220970903292975

Klassen, R., \& Chiu, M. M. (2010). Effects of Teachers' Self-Efficacy and Job Satisfaction: Teacher Gender, Years of Experience, and Job Stress. Journal of Educational Psychology, 102, 741-756. https://doi.org/10.1037/a0019237

Klassen, R., \& Chiu, M. M. (2011). The Occupational Commitment and Intention to Quit of Practicing and Pre-Service Teachers: Influence of Self-Efficacy, Job Stress, and Teaching Context. Contemporary Educational Psychology, 36, 114-129. https://doi.org/10.1016/j.cedpsych.2011.01.002

Klassen, R., Wilson, E., Siu, A. F. Y., Hannok, W., Wong, M. W., Wongsri, N., Jansem, A. et al. (2013). Preservice Teachers' Work Stress, Self-Efficacy, and Occupational Commitment in Four Countries. European Journal of Psychology of Education, 28, 1289-1309. https://doi.org/10.1007/s10212-012-0166-x

Kokkinos, C. M. (2007). Job Stressors, Personality and Burnout in Primary School Teachers. British Journal of Educational Psychology, 77, 229-243.

https://doi.org/10.1348/000709905X90344

Kurt, T., Duyar, I., \& Calik, T. (2012). Are We Legitimate Yet?: A Closer Look at the Casual Relationship Mechanisms among Principal Leadership, Teacher Self-Efficacy and Collective Efficacy. Journal of Management Development, 31, 71-86. https://doi.org/10.1108/02621711211191014

Li, M., Wang, Z., Gao, J., \& You, X. (2017). Proactive Personality and Job Satisfaction: The Mediating Effects of Self-Efficacy and Work Engagement in Teachers. Current Psychology, 36, 48-55. https://doi.org/10.1007/s12144-015-9383-1

Linnenbrink, E. A., \& Pintrich, P. R. (2003). The Role of Self-Efficacy Beliefs in Student Engagement and Learning in the Classroom. Reading and Writing Quarterly, 19, 119-137. https://doi.org/10.1080/10573560308223

Little, R. J. A., \& Rubin, D. B. (1989). The Analysis of Social Science Data with Missing Values. Sociological Methods and Research, 18, 292-326. https://doi.org/10.1177/0049124189018002004

Malinen, O.-P., \& Savolainen, H. (2016). The Effect of Perceived School Climate and Teacher Efficacy in Behavior Management on Job Satisfaction and Burnout: A Longitudinal Study. Teaching and Teacher Education, 60, 144-152.

https://doi.org/10.1016/j.tate.2016.08.012

McMahon, S. D., Parnes, A. L., Keys, C. B., \& Viola, J. J. (2008). School Belonging among Low-Income Urban Youth with Disabilities: Testing a Theoretical Model. Psychology 
in the Schools, 45, 387-401. https://doi.org/10.1002/pits.20304

Mojavezi, A., \& Tamiz, M. P. (2012). The Impact of Teacher Self-Efficacy on the Students' Motivation and Achievement. Theory and Practice in Language Studies, 2, 483-491. https://doi.org/10.4304/tpls.2.3.483-491

Muthén, B., Kaplan, D., \& Hollis, M. (1987). On Structural Equation Modeling with Data That Are Not Missing Completely at Random. Psychometrika, 52, 431-462. https://doi.org/10.1007/BF02294365

Pajares, F. (1997). Current Directions in Self-Efficacy Research. In M. M. Maehr, \& P. R. Pintrich (Eds.), Advances in Motivation and Achievement (pp. 1-49). Greenwich, CT: JAI Press.

Parks, M., Solmon, M., \& Lee, A. (2007). Understanding Classroom Teachers' Perceptions of Integrating Physical Activity: A Collective Efficacy Perspective. Journal of Research in Childhood Education, 21, 316-328. https://doi.org/10.1080/02568540709594597

Pines, A., \& Aronson, E. (1988). Career Burnout. Causes and Cures. New York: The Free Press.

Roeser, R. W., Midgley, C., \& Urdan, T. C. (1996). Perceptions of the School Psychological Environment and Early Adolescents' Psychological and Behavioral Functioning in School: The Mediating Role of Goals and Belonging. Journal of Educational Psychology, 88, 408-422. https://doi.org/10.1037/0022-0663.88.3.408

Rosenberg, M. (1977). Contextual Dissonance Effects: Nature and Causes. Psychiatry, 40, 205-217. https://doi.org/10.1080/00332747.1977.11023934

Rosenberg, M. (1979). Conceiving the Self. New York: Basic Books.

Sahlberg, P. (2010). Rethinking Accountability in a Knowledge Society. Journal of Educational Change, 11, 45-61. https://doi.org/10.1007/s10833-008-9098-2

Saricam, H., \& Sakiz, H. (2014). Burnout and Teachers' Self-Efficacy among Teachers Working in Special Education in Turkey. Educational Studies, 40, 423-437. https://doi.org/10.1080/03055698.2014.930340

Schafer, J. L. (1997). Analysis of Incomplete Multivariate Data. London: Chapman \& Hall.

Schaufeli, W. B., Bakker, A. B., \& Salanova, M. (2006). The Measurement of Work Engagement with a Short Questionnaire. A Cross-National Study. Educational and Psychological Measurement, 66, 701-716. https://doi.org/10.1177/0013164405282471

Schaufeli, W. B., Salanova, M., González-Romá, V., \& Bakker, A. B. (2002). The Measurement of Engagement and Burnout: A Two Sample Confirmatory Factor Analytic Approach. Journal of Happiness Studies, 3, 71-92. https://doi.org/10.1023/A:1015630930326

Shernoff, E. S., Mehta, T. G., Atkins, M. S., Torf, R., \& Spencer, J. (2011). A Qualitative Study of the Sources and Impact of Stress among Urban Teachers. School Mental Health, 3, 59-69. https://doi.org/10.1007/s12310-011-9051-z

Shochet, I. M., Dadds, M. R., Ham, D., \& Montague, R. (2006). School Connectedness Is an Underemphasized Parameter in Adolescent Mental Health: Results of a Community Prediction Study. Journal of Clinical Child and Adolescent Psychology, 35, 170-179. https://doi.org/10.1207/s15374424jccp3502_1

Shoji, K., Cieslak, R., Smoktunowicz, E., Rogala, A., Benight, C. C., \& Luszczynska, A. (2016). Associations between Job Burnout and Self-Efficacy: A Meta-Analysis. Anxiety, Stress, and Coping, 29, 367-386. https://doi.org/10.1080/10615806.2015.1058369

Simbula, S., Guglielmi, D., \& Schaufeli, W. B. (2011). A Three-Wave Study of Job Resources, Self-Efficacy, and Work Engagement among Italian Schoolteachers. European Journal of Work and Organizational Psychology, 20, 285-304. 
https://doi.org/10.1080/13594320903513916

Skaalvik, E. M., \& Skaalvik, S. (2007). Dimensions of Teacher Self-Efficacy and Relations with Strain Factors, Perceived Collective Teacher Efficacy, and Teacher Burnout. Journal of Educational Psychology, 99, 611-625. https://doi.org/10.1037/0022-0663.99.3.611

Skaalvik, E. M., \& Skaalvik, S. (2010). Teacher Self-Efficacy and Teacher Burnout: A Study of Relations. Teaching and Teacher Education, 26, 1059-1069. https://doi.org/10.1016/j.tate.2009.11.001

Skaalvik, E. M., \& Skaalvik, S. (2011a). Teacher Job Satisfaction and Motivation to Leave the Teaching Profession: Relations with School Context, Feeling of Belonging, and Emotional Exhaustion. Teaching and Teacher Education, 27, 1029-1038. https://doi.org/10.1016/j.tate.2011.04.001

Skaalvik, E. M., \& Skaalvik, S. (2011b). Teachers' Feeling of Belonging, Exhaustion, and Job Satisfaction: The Role of Goal Structure and Value Consonance. Anxiety, Stress, and Coping: An International Journal, 24, 369-385. https://doi.org/10.1080/10615806.2010.544300

Skaalvik, E. M., \& Skaalvik, S. (2014). Teacher Self-Efficacy and Perceived Autonomy: Relations with Teacher Engagement, Job Satisfaction, and Emotional Exhaustion. Psychological Reports, 114, 68-77. https://doi.org/10.2466/14.02.PR0.114k14w0

Skaalvik, E. M., \& Skaalvik, S. (2015). Job Satisfaction, Stress and Coping Strategies in the Teaching Profession-What Do Teachers Say? International Education Studies, 8, 181-192. https://doi.org/10.5539/ies.v8n3p181

Skaalvik, E. M., \& Skaalvik, S. (2016). Teacher Stress and Teacher Self-Efficacy as Predictors of Engagement, Emotional Exhaustion, and Motivation to Leave the Teaching Profession. Creative Education, 7, 1785-1799. https://doi.org/10.4236/ce.2016.713182

Skaalvik, E. M., \& Skaalvik, S. (2017a). Still Motivated to Teach? A Study of School Context Variables, Stress and Job Satisfaction among Teachers in Senior High School. Social Psychology of Education, 20, 15-37. https://doi.org/10.1007/s11218-016-9363-9

Skaalvik, E. M., \& Skaalvik, S. (2017b). Motivated for Teaching? Associations with School Goal Structure, Teacher Self-Efficacy, Job Satisfaction and Emotional Exhaustion. Teaching and Teacher Education, 67, 152-160. https://doi.org/10.1016/j.tate.2017.06.006

Skaalvik, E., M., \& Skaalvik, S. (2017c). Dimensions of Teacher Burnout: Relations with Potential Stressors at School. Social Psychology of Education, 20, 775-790.

https://doi.org/10.1007/s11218-017-9391-0

Stephanou, G., \& Oikonomou, A. (2018). Teacher Emotions in Primary and Secondary Education: Effects of Self-Efficacy and Collective-Efficacy, and Problem-Solving Appraisal as a Moderating Mechanism. Psychology, 9, 820-875.

https://doi.org/10.4236/psych.2018.94053

Tschannen-Moran, M., \& Woolfolk Hoy, A. (2007). The Differential Antecedents of Self-Efficacy Beliefs of Novice and Experienced Teachers. Teaching and Teacher Education, 23, 944-956. https://doi.org/10.1016/j.tate.2006.05.003

Viel-Ruma, K., Houchins, D., \& Jolivette, K. (2010). Efficacy Beliefs of Special Educators: The Relationships among Collective Efficacy, Teacher Self-Efficacy, and Job Satisfaction. Teacher Education and Special Education, 33, 225-233. https://doi.org/10.1177/0888406409360129

Zee, M., \& Koomen, H. M. Y. (2016). Teacher Self-Efficacy and Its Effects on Classroom Processes, Student Academic Adjustment, and Teacher Well-Being. A Synthesis of 40 Years of Research. Review of Educational Research, 86, 981-1015.

https://doi.org/10.3102/0034654315626801 